\title{
Padrões de concordância de gênero e número no sintagma nominal em variedades africanas do português
}

\author{
Adeilson Pinheiro Sedrins ${ }^{1}$
}

Cláudia Roberta Tavares Silva²

\section{Resumo}

Estudos sociolinguisticos realizados no âmbito da concordância verbal (CV) e nominal (CN) no português brasileiro (PB) e no português europeu (PE) apontam que, no primeiro, tanto a $C N$ quanto a $C V$ constituem uma regra variável, ao passo que, no segundo, uma regra categórica no âmbito da CN (99,9\%) e semicategórica no âmbito da CV (98,9\%) (BRAND AO; VIEIRA, 2012). Neste artigo, centrando nossa atenção nos padrões de $C N$ de gênero e número em cinco variedades africanas do português (Angola, Moçambique, São Tomé e Principe, Cabo Verde e Guiné-Bissau) e, tomando por base as três classes de regras linguísticas propostas por Labov (2003), verificamos, no corpus desta pesquisa, constituido de 13.432 sintagmas, uma regra variável e semicategórica para a CN de número. Quanto ao gênero, os resultados percentuais sugerem que a regra de aplicação da concordância se apresenta categórica no português de Angola e semicategórica nas demais variedades africanas do português.

Palavras-chave: Variação. Concordância nominal. Número. Gênero. Variedades africanas do português

\footnotetext{
1 Professor de Língua Portuguesa do Curso de Licenciatura em Letras da UFRPE/UAST. Doutor em Linguística pela Universidade Federal de Alagoas. Vice-líder do Grupo de Estudos em Teoria da Gramática (GETEGRA) e membro do Programa de Estudos Linguísticos (PRELIN), vinculado ao Programa de PósGraduação em Letras e Linguística da UFAL.

2 Universidade Federal Rural de Pernambuco.
} 


\section{Introdução}

Este trabalho aborda o português falado na África, centrando a atenção no aspecto morfossintático da concordância de número e gênero no sintagma nominal. Longe de ser uma abordagem generalizante desse português devido à complexidade linguística no continente africano evidenciada pelo seu convívio com outras línguas, adotaremos aqui a terminologia variedades africanas do português que abarca o português de Angola (PA), Moçambique (PM), Guiné-Bissau (PGB), São Tomé e Príncipe (PSTP) e Cabo Verde (PCV). Sobre o contato multilinguístico, destaca Mattos e Silva (1988, p. 16): “[c]ontrariamente ao que ocorre no português europeu, em todas as outras áreas lusófonas, o português se encontra em situações complexas e diversas de multilinguismo e aí está incluído o Brasil”. Apesar desse ponto de convergência entre o Brasil e a África, estudos linguísticos revelam que as variedades africanas do português apresentam usos mais próximos da norma europeia do português (doravante, PE) (BACELAR DO NASCIMENTO et al., 2008; MOTA, 2015).

Ademais, um aspecto que merece destaque é que, ao contrário do português brasileiro (doravante, PB), cujo processo de gramatização inicia-se no século XIX logo após sua independência de Portugal (FARACO; VIEIRA, 2016), nos países africanos cujo processo de independência é recente, um processo de gramatização africana do português ainda não foi consolidado, o que parece justificar o uso do termo tendências, embora já vislumbremos iniciativas que sinalizem para esse processo (MINGAS, 1998; LORENZINO, 1996; ARAKAKY, 2014; GONÇALVES, 2015; NZAU; VENÂNCIO; SARDINHA, 2013; TEIXEIRA; ALMEIDA, 2011). Comparando o PM e o PA com o PB, Petter (2009) observa que este apresenta uma relativa estabilidade no sentido de que há uma menor variação na concordância de gênero, ao contrário daqueles que ainda possuem um contato recente com o PE e recebem influência das línguas bantu (língua materna dos falantes). Falantes dessas línguas, sobretudo, os mais velhos e os menos escolarizados (INVERNO, no prelo; GONÇALVES, 2015) têm dificuldade de aprender a flexão de gênero em português, pois suas línguas maternas não apresentam distinção entre masculino e feminino (INVERNO, 2004), o que os leva a produzirem sintagmas nominais como os que se seguem:

a. "Eu tenho minhas netos." (M) (GONÇALVES, 2015, p. 12)

b. "esses visita" (A) (INVERNO, no prelo, p. 6) 
Assumimos, como Mota (2015), neste trabalho, que "[é] importante que as investigações linguísticas sobre as variedades não europeias do português estejam atreladas à pesquisa histórico-sociológica, a fim de se entender a influência do possível contato linguístico entre essas variedades e outras línguas". Nesse sentido, é fundamental que levemos em conta a complexidade linguística de cada país africano onde se fala o português: "[n]a África, embora seja língua oficial, que é utilizada na administração e no ensino, o português é adquirido, prioriariamente, como segunda língua, que tem por modelo a variedade européia" (PETTER, 2009, p. 203).

O português constitui-se língua oficial em todos os países aqui investigados, embora não seja a língua mais falada em comparação às línguas do grupo bantu faladas em Moçambique e em Angola e as línguas crioulas faladas em Cabo Verde e Guiné-Bissau.

Em se tratando de Guiné-Bissau, por exemplo, o português é muito pouco falado em relação ao crioulo guineense, diferentemente do que ocorre em São Tomé e Príncipe (GONÇALVES, 2012) que é o "único país da África de língua portuguesa onde a maioria da população tem actualmente o Português como primeira língua, havendo assim condição para a emegência de uma nova variedade" (HAGEMEIJER, 2009, p. 19-20).

Levando em consideração os resultados de pesquisas que apontam para uma maior proximidade entre as variedades africanas do português e a norma europeia do português e de que o português é a língua oficial nos países em análise cujo multilinguísmo é intenso, este artigo centra a atenção na concordância de número e gênero no sintagma nominal em variedades africanas do português, pois, até onde temos verificado, ainda são recentes e escassas as pesquisas sobre esse fenômeno quando levados em conta os cinco países africanos de língua oficial portuguesa (PETTER, 2009; ADRIANO, 2014; INVERNO, 2004; FIGUEIREDO, 2010; BRANDÃO; VIEIRA, 2012; OLIVEIRA, SOLEDADE; SANTOS, 2009; NZAU, VENÂNCIO, SARDINHA, 2013; JON-AND, 2010; GONÇALVES, 2015; OLIVEIRA, BAIO; INJAI, 2013; GONÇALVES, 2012; LUCCHESI; BAXTER; RIBEIRO, 2009, LUCCHESI, 2012).

É, portanto, objetivo central desta pesquisa discutir os padrões de concordância nominal encontrados nas cinco variedades africanas do português, observando em que medida esses padrões apresentam simetrias/assimetrias com os padrões encontrados em variedades brasileiras do português, haja vista a concordância nominal ser uma regra categórica no PE (BRANDÃO; VIEIRA, 2012). 
Os dados que compõem o corpus desta pesquisa, totalizando 13.432 sintagmas, foram extraídos de 74 entrevistas informais, sendo 15 de Angola, 12 de Moçambique, 18 de Guiné-Bissau, 19 de Cabo Verde e 10 de São Tomé e Príncipe. Essas entrevistas integram o projeto Variedades Africanas do Português (VAPOR), do Centro de Linguística da Universidade de Lisboa (CLUL/UL), coordenado pelos professores Tjerk Hagemeijer e Amália Mendes ${ }^{3}$.

Em linhas gerais, este artigo encontra-se assim estruturado: na seção seguinte, serão retomados estudos que enfocam fenômenos de concordância nas variedades em estudo a partir de um viés sociolinguístico; em seguida, será realizada a análise dos dados, a partir da qual serão explorados os padrões de concordância nominal, tendo em mente também padrões encontrados em variedades do PB e, na seção posterior, serão apresentadas as considerações finais.

\section{Sobre a concordância em variedades africanas do português: breves incursões}

Em seu estudo sobre a concordância verbal no PGB, Romão (2012 apud SANTOS, 2015, p. 39) ${ }^{4}$ verifica que os casos de ausência de concordância verificados como em (2) têm sido atribuídos à transferência da língua materna dos falantes, a saber: o crioulo guineense cuja forma verbal carece dos morfemas número-pessoais e modo-temporais (CASTRO, 2013), uma característica também verificada em outros crioulos de base lexical portuguesa (PRATAS, 2002, 2007; HAGEMEIJER, 2007, MAURER, 2013):

(2) a.eles foi salvo

b. os tupinambás... tinha ido

c os franceis fui

No âmbito da concordância de gênero no sintagma nominal, Couto e Embaló (2010) observam casos de ausência da flexão de gênero no PGB (ver [3]) e atribuem a esses

\footnotetext{
3 Para maiores informações, conferir o site do projeto: http://www.clul.ul.pt/pt/recursos/184-vapor-africanvarieties-of-portuguese. Agradecemos ao professor Tjerk Hagemeijer por permitir o acesso aos dados sem os quais não seria possível a realização deste estudo.

${ }_{4}^{4}$ Os dados apresentados em (2) foram extraídos de textos dissertativos produzidos por alunos guineenses de graduação que cursavam um curso de língua portuguesa promovido pelo Centro de línguas da Universidade de São Paulo.
} 
usos a interferência do crioulo guineense em que "a distinção entre o gênero masculino e feminino é quase inexistente" (CASTRO, 2013, p. 99):
a. "o $\underline{\text { meu }} i r m a ̈$ "
b. "meu mãe"
c. "ele tem três filho fêmea"

Brandão e Vieira (2012, p. 1055), por sua vez, realizando um estudo sociolinguístico sobre a concordância verbal e nominal em que são comparados o PE (cidade: Cacém), o PB (cidade: Nova Iguaçu) e o PST (cidade: São Tomé), concluem, tomando por base as regras linguísticas propostas por Labov (2003): regra categórica (100\%), semicategórica (9599\%) e variável (5-95\%), que no PE, independentemente do grau de escolaridade ${ }^{5}$ do falante, a concordância nominal é categórica $(99,9 \%)$ e a concordância verbal, semicategórica (98,9\%). Ainda, apontam que no PST e no PB, o grau de escolaridade exerce influência para o uso da variante padrão relacionado às duas concordâncias. Quanto maior o grau de escolaridade do informante, maior a aplicação da regra de concordância nominal e verbal. Nessas duas variedades, a regra é variável: a) no PST (concordância verbal: $93,1 \%$ e concordância nominal: $93,4 \%$ ) e b) no PB (concordância verbal: 78,1\% e concordância nominal: 91,1\%).

Analisando o português de Moçambique, Gonçalves observa também que

[q]uanto às inovações morfológicas (como, por exemplo, o enfraquecimento da morfologia de flexão nominal e verbal), verifica-se que estas são produzidas por falantes pouco escolarizados, ou, nos casos em que apresentam uma distribuição social mais ampla, dizem respeito a fenómenos muito específicos [...] (GONÇALVES, 2000, p. 3).

Essa distribuição social mais ampla a que se refere a autora diz respeito a falantes com nível superior cujo uso linguístico é muito próximo à norma europeia do português. Sobre essa questão, ressaltam Mota, Miguel e Mendes (2012, p. 168) para o PCV e o PA: “[...] os

\footnotetext{
${ }^{5}$ Vale referirmos que o Banco de Dados a que tivemos acesso apresenta uma distribuição muito assimétrica no que se refere ao sexo e ao grau de escolaridade (este último, às vezes, não vem especificado) dos falantes africanos nos cinco países, o que nos impossibilitou, neste momento, de realizarmos uma análise quantitativa dessas variáveis, seguindo o viés da Socilinguística Quantitativa. Nesse sentido, conforme já enunciamos, é nosso objetivo neste artigo verificarmos os padrões estruturais encontrados de CN de número e gênero para que, a partir dos resultados percentuais obtidos, possamos observar qual é o tipo de regra linguística, tomando por base Labov (2003).
} 
dados da norma urbana culta em Angola e Cabo Verde dão indícios de esta ser mais próxima da do PE do que da brasileira [...]”. Ainda sobre o PCV, Mota observa que

\begin{abstract}
é a variedade em que a concordância está mais próxima da tida como canónica, seguindo-se Luanda e S. Tomé. Este padrão canónico é, em Cabo Verde, um alvo a atingir pelos falantes cultos, como Lopes 2011 refere. Os cabo-verdianos são em geral críticos relativamente a reconhecer um standard de Português cabo-verdiano que se afaste muito do europeu. Os entrevistados ${ }^{6}$ por Lopes, em 2005-06, afirmam sentirem-se destabilizados e preocupados pelos 'erros' que cometem em Português e, curiosamente, referem como erros mais frequentes a 'falta de concordância' [...] (MOTA, 2015, p. 35).
\end{abstract}

Em linhas gerais, Brandão e Vieira (2012) observam que os dados orais da fala urbana no PB e no PST compartilham do resultado de terem sido selecionadas como as mais significativas para o favorecimento da marca explícita de plural no $\mathrm{SN}$ as variáveis: a) posição linear e relativa do constituinte no $S N$ (elementos à esquerda do núcleo na primeira posição) e b) nivel de escolaridade (quanto mais escolarizado o falante, maior a aplicação da regra) (GONÇALVES, 2012). Ademais, é proposto pelas autoras o continuum de marcação de pluralidade que vai do polo [+marcas] no domínio pré-núcleo ao polo [-marcas] no domínio pós-núcleo. Por exemplo, um mesmo constituinte, quando altera sua posição em relação ao núcleo, evidencia esse continuum (como em (4a) e (4b) versus (4c) e (4d)):
a. $\underline{\text { todos }}$ os seus aluno
b. ter boas ideia
c. aquelas coisa toda
d. ter condições financeira boa

Em suma, as autoras concluem que o PB e o PST revelam uma situação sociolinguística polarizada evidenciada pelo "efeito do contato entre línguas (Ibid., p. 1041). Segundo as autoras, isso se evidencia em PB quando contrastada a norma urbana culta (94\% de aplicação da regra) (GRACIOSA, 1991) com as comunidades rurais afrobrasileiras (16\% de aplicação da regra) (LUCCHESI; BAXTER; RIBEIRO, 2009), onde o contato do português com as línguas africanas foi bastante intenso. No caso do PST, foi

\footnotetext{
${ }^{6}$ Foram entrevistados 14 informantes da ilha da Praia que são falantes bilíngues Português-Crioulo de Cabo Verde. O corpus encontra-se disponível no site http:// repositorio.ul.pt/.
} 
observado que quanto maior a frequência do uso de uma língua crioula, maior a tendência de o falante não implementar a marca de número.

Analisando a concordância de número no PCV que não possui substrato bantu, Jon-And (2010) observa uma tendência à marcação de plural apenas no primeiro elemento do SN. Nesse caso, a explicação reside na influência do crioulo caboverdiano (em específico, do crioulo falado em São Vicente analisado por essa autora), língua materna dos falantes, cuja marca de plural no SN ocorre no primeiro elemento desse sintagma. No entanto, a autora reconhece a necessidade de "uma análise mais profunda e detalhada da marcação de plural nos substratos do crioulo de Cabo Verde, e a eventual sobrevivência dessas estruturas no crioulo de Cabo Verde" (p. 45).

No que se refere ao gênero, não sendo essa categoria especificada nas línguas bantu, é possível encontrar dados do PA e do PM em que há ausência de concordância de gênero, conforme apresentado em Petter (2009, p. 208): "brincadera bruto; meninada... acostumado; porta... aberto; cidade...idêntico; condições...bom". Segundo verifica Adriano (2014, p. 203), esses dados são produzidos em zonas suburbanas ou mesmo rurais por falantes com pouca ou nenhuma escolaridade.

Tomando por base as considerações feitas nesta seção, passemos à análise contrastiva dessas variedades, tendo em mente os padrões estruturais de concondância encontrados para o número e o gênero.

\section{A concordância nominal em variedades africanas do português}

Nossa análise buscou verificar, para os casos de não-aplicação de concordância, se havia uma regularidade nessa não-marcação e qual(quais) seria(m). Tendo em mente os resultados de pesquisas sobre o mesmo fenômeno em variedades do PB (principalmente os percentuais apresentados na pesquisa de BRANDÃO \& VIEIRA, 2012), apontamos simetrias e assimetrias entre o padrão verificado nessa língua e as variedades africanas selecionadas. Para a análise da concordância nominal, a seleção dos dados foi realizada em dois momentos distintos: num primeiro momento, foram selecionados do corpus os SNs plurais, para proceder à análise da concordância de número; e, no segundo momento, 
foram selecionados todos os $\mathrm{SNs}$, de cada variedade, a fim de verificarmos a concordância de gênero entre elementos pré e pós-nominais com os núcleos nominais

\section{A concordância de número}

No quadro abaixo, apresentamos o número de SNs plurais selecionados para a análise em cada uma das variedades africanas, bem como o percentual de aplicação e nãoaplicação da concordância de número:

\begin{tabular}{|c|c|c|c|}
\hline Localidade & Total geral & $\begin{array}{c}\% \text { Aplicą̧ão da } \\
\text { concordância }\end{array}$ & \% Não-aplicação da \\
\hline Angola & 485 & & Concordância \\
\hline Cabo Verde & 794 & $772(97 \%)$ & $39(8 \%)$ \\
\hline Guiné Bissau & 912 & $865(95 \%)$ & $20(3 \%)$ \\
\hline Moçambique & 803 & $768(96 \%)$ & $35(5 \%)$ \\
\hline São Tomé e Príncipe & 484 & $464(96 \%)$ & $20(4 \%)$ \\
\hline
\end{tabular}

Quadro 1: Resultados para a concordância de número nas variedades africanas.

Os resultados, no quadro acima, apontam para uma preferência à aplicação da concordância nominal, uma tendência apresentada em outras variedades do português, como a variedade do PB investigada por Brandão e Vieira (2012). No entanto, tomando por base as três regras linguísticas propostas por Labov (2003), verificamos que apenas em Angola a aplicação da regra se mostra variável (com 92\% de aplicação da concordância), ao contrário das demais variedades em que se apresenta como semicategórica (95\% a 97\%).

A fim de buscarmos apresentar regularidades na não-aplicação de concordância de número, iremos discutir os tipos de estruturas de $\mathrm{SN}$ encontrados em cada variedade. No que diz respeito aos dados de $\mathrm{PA}$, dos $39 \mathrm{SNs}$ que não apresentaram a aplicação da concordância, 35 (90\%) apresentaram a marcação de pluralidade apenas no primeiro 
elemento, uma tendência fortemente observada em variedades do $\mathrm{PB}^{7}$. Exemplos desse tipo são apresentados em (5):
a. uns saco (AI1) 8
b. muitas coisa (AI1)
c. das mão (AI2)
d. dessas amostra (AI5)

Apenas 4 casos apresentaram um padrão diferenciado, sem marcação no primeiro elemento do SN, os quais apresentamos a seguir:
a. do quarenta (AI5)
b. na tuas lavra (AI9)
c. essa pessoas (AI15)
d. o indivíduos (AI8)

Com exceção do exemplo em (6d), observamos um padrão que se mostra recorrente também nas outras variedades africanas aqui analisadas. (6a) e (6b) são introduzidos pela aglutinação da preposição a um artigo definido. (6c) é introduzido por um demonstrativo e, (6d), finalmente, é introduzido por um artigo definido, seguido pelo núcleo nominal no plural.

Em relação aos dados de PCV, dos 20 casos de não-marcação de concordância nominal de número, 13 (65\%) seguem a mesma tendência observada em variedades do PB, a de marcação em elementos pré-nominais, como observamos nos exemplos em (7):

\footnotetext{
${ }^{7}$ Ver, nesse sentido, a análise apresentada em Scherre (1998). De acordo com os resultados encontrados pela autora, "a primeira posição do SN é o fator que mais favorece a inserção da marca formal de plural, ocorrendo uma queda brusca em relação às demais posições, as quais tendem a desfavorecer de forma decrescente a presença da marca formal de plural no SN” (SCHERRE, 1998, p. 92).

${ }^{8}$ Dentro dos parênteses, encontram-se as seguintes informações: A(Angola), I(informante) e o número do informante (1).
} 
(7) a. vinte e uma erupção (CVI14)

b. As zonas menos afetada (CVI14)

c. situações difícil (CVI10)

7 casos, entre os 20 encontrados sem aplicação da concordância, não seguem o padrão produtivo encontrado em variedades do PB. Contudo, é possível observarmos dois contextos bem delineados: (a) SNs encabeçados por quantificadores, com ausência da marca de plural no quantificador, como em (8a) - três ocorrências desse tipo foram verificadas, e (b) SNs em que o artigo definido está aglutinado a uma preposição, não marcado para plural, como mostra o exemplo em (8b):

(8) a. Toda essas tarefas (CVI16)

b. Na gerações jovem (CVI19)

(8b) é o mesmo contexto observado com o mesmo padrão de não aplicação de concordância para os dados de PA apresentados em (6a) e (6b).

Já no que diz respeito aos dados de PGB, observamos que dos $47 \mathrm{SNs}$ plurais em que não ocorre a aplicação da concordância, 32 casos apresentam padrões encontrados no $\mathrm{PB}$, como os apresentados em (9), contra 15 ocorrências que apresentam um padrão que se distancia dessa língua, como os casos apresentados em (10):

(9) a. As família (GBI16)

b. Várias escola (GBI16)

(10) a. Muito medicamentos naturais (GBI5)

b. Da mulheres (GBI4)

c. Esse boîtes (GBI9)

d. O crentes (GBI5)

e. Camada juvenis (GBI10) 
Em (10a) temos uma estrutura também observada em dados do PCV (8a), com quantificador ocupando a primeira posição, sendo não marcado para plural. Foram encontradas 5 ocorrências desse tipo de não marcação nos dados de PGB. Essas 5 ocorrências correspondem a $25 \%$ do tipo de padrão de concordância que se distancia daquela verificada comumente em variedades do PB. Com a mesma quantidade de ocorrências, temos construções como a apresentada em (10b), em que o SN é introduzido por um artigo definido aglutinado com a preposição e não marcado para plural. Esse tipo de ocorrência também foi encontrada nos dados de PA (6b) e nos dados de PCV (7a) e (7b).

Pouco ou até mesmo não recorrentes são dados dos tipos apresentados em (10c), (10d) e (10e). Nos dois primeiros exemplos, o núcleo nominal é marcado para plural e o determinante, na primeira posição, não é marcado. Em (10e), o núcleo nominal está na primeira posição, não-marcado para plural, e o adjetivo, em segunda posição, é que vem marcado.

No que diz respeito aos dados do PM, observamos que, dos $35 \mathrm{SNs}$ plurais em que não se dá a aplicação da concordância, 24 casos (69\%) apresentam a tendência de marcação nos itens pré-nucleares, como o PB, e 11 (31\%) casos apresentam ocorrências não produtivas nessa variedade. Em (11) há marcação de plural apenas no primeiro elemento do $\mathrm{SN}$, enquanto em (12) vemos a marcação apenas no elemento localizado à direita do $\mathrm{SN}$ :

a. Os casamento de hoje (MI2)

b. As criança (MI4)

a. Numa barracas (MI6)

b. Muito lares (MI12)

c. Esse machibombos (MI12)

d. O alimentos (MI9)

e. O transporte suficientes (MI3) 
f. base químicos (MI1)

Construções do tipo apresentado em (12a) ocorrem apenas duas vezes no corpus do PM. Contudo, é pertinente observarmos que esse tipo de construção, em que o primeiro elemento do SN está aglutinado à preposição e não-marcado para plural, aparece também nos dados já discutidos do PA (6a, 6b), do PCV (7b) e do PGB (10b). Da mesma forma, a não-marcação de plural, como a apresentada em (12b), em que o SN é introduzido por um quantificador e este não recebe marca de pluralidade, manifesta-se também no PCV (7a) e no PGB (10a). Dados como o apresentado em (12c), em que o SN é introduzido por um demonstrativo não-marcado para plural, também aparece no PA (6c) e no PGB (10c).

Vale referirmos que o sintagma em (12c) aparece apenas uma única vez, apesar de ter aparecido uma ocorrência também no PGB (10d) e no PA (6d). Todavia, se agruparmos sintagmas do tipo (12c) e (12d), observando que ambos apresentam uma mesma estrutura, a saber, a estrutura [Det (artigo ou demonstrativo) $+N_{\text {plu }}$, alcançamos uma generalização para um maior número de dados. Ao considerarmos esse tipo de estrutura, observamos sua recorrência em dados como (6c) e (6d) do PA, (7a) do PCV, (19a) e (19b) do PGB.

Os sintagmas (12e) e (12f) apresentam a marcação apenas no elemento pós-nuclear, um adjetivo, sendo encontrado também no PGB (10e) com apenas uma ocorrência.

No PST, apenas $20 \mathrm{SNs}$ plurais não apresentaram aplicação da regra de concordância em todos os itens pluralizáveis. Desse número, 18 ocorrências seguem a tendência de marcar os elementos pré-nucleares localizados à direita do $\mathrm{SN}$, como mostram os dados em (13) e apenas 2 ocorrências apresentam um padrão de marcação fora daquele observado na maioria dos casos, com marcação apenas no núcleo nominal, sem marcação nos itens pré-nucleares, como mostra (14):

a. os nosso marido (STI5)

b. Alguns conhecimento (STI6)

a. Todo o dilemas (STI2)

b. Uma bolsas de estudo (STI4) 
Os dados de (13) apresentam uma recorrência do que já foi observado nas outras variedades aqui investigadas. Trata-se de SNs introduzidos por quantificadores não marcados para plural'.

Buscando sistematizar os tipos de estruturas observadas, atreladas ao fenômeno da concordância de número, podemos chegar às seguintes observações:

(a) Observa-se, a partir dos resultados percentuais obtidos, que no PM, no PGB, no PST e no PCV, a regra de CN é semicategórica, ao passo em que no PA, variável;

(b) Os dados referentes à não-aplicação da regra de concordância em todos os itens pluralizáveis do SN tendem também a seguir uma tendência já observada para variedades do PB, que é a do favorecimento da marcação para elementos localizados à esquerda do SN. Isso é constatado para as cinco variedades;

(c) Nas cinco variedades analisadas, encontramos casos que não se aproximam do padrão encontrado no PB, de marcação preferencial em itens localizados à esquerda do SN. Esses casos, no entanto, são em número reduzido, considerado, principalmente, ao número total de $\mathrm{SNs}$ analisados;

(d) É possível entrevermos uma estruturação, embora muito pequena, nos casos de não-aplicação de concordância nas cinco variedades: (i) não-marcação de plural em quantificadores na primeira posição; (ii) não-marcação de plural no artigo definido quando este se aglutina a uma preposição, e (iii) não-marcação de plural no determinante em estruturas do tipo $\left[\operatorname{det}_{\text {(artigo ou demonstrativo) }}+\mathrm{N}_{\mathrm{p}}\right]$.

As observações acima permitem estabelecer um paralelo entre as variedades africanas do português e variedades do $\mathrm{PB}$, ao mesmo tempo em que podem sugerir que as peculiaridades observadas em (d) possam ser fruto da interação de fatores peculiares à realidade sócio-histórica e linguística em que essas variedades são utilizadas.

\section{A concordância de gênero}

O quadro abaixo apresenta o resultado da análise da concordância de gênero nas cinco variedades africanas do português. Apresentamos o total de SNs selecionados em

\footnotetext{
${ }^{9}$ Estamos assumindo aqui o caráter de quantificador para o que tradicionalmente se convencionou chamar de artigo indefinido. Ver, a esse respeito, Castilho (2010).
} 
cada variedade, bem como o número de ocorrência da aplicação e não-aplicação da concordância:

\begin{tabular}{|c|c|c|c|}
\hline Localidade & Total geral & $\begin{array}{c}\% \text { Aplicaşão da } \\
\text { CN } S N s\end{array}$ & $\begin{array}{c}\text { \% Não-aplicação da } \\
\text { da CN }\end{array}$ \\
\hline Angola & 1997 & $1997(100 \%)$ & 0 \\
\hline Cabo Verde & 2827 & $2818(99,7 \%)$ & $9(0,3 \%)$ \\
\hline Guiné Bissau & 3174 & $3119(98 \%)$ & $55(2 \%)$ \\
\hline Moçambique & 3352 & $3340(99,6 \%)$ & $12(0,4 \%)$ \\
\hline São Tomé e Príncipe & 2082 & $2078(99,8 \%)$ & $4(0,2 \%)$ \\
\hline
\end{tabular}

Quadro 2: Resultado da variação da concordância de gênero no SN nas variedades africanas.

Os resultados percentuais obtidos revelam, por um lado, que, ao contrário do que se observa para a $\mathrm{CN}$ de número no PA que se apresenta como variável, a concordância de gênero nessa variedade apresenta-se como categórica (100\%). Por outro lado, nas demais variedades, a $\mathrm{CN}$ de gênero apresenta-se como semicategórica, à semelhança da $\mathrm{CN}$ de número, valendo referirmos que os percentuais são mais elevados naquela (98\% a 99,8\%).

Compararmos os padrões da $\mathrm{CN}$ de gênero encontrados nos dados das variedades africanas a padrões do PB requer considerarmos o fato de que, praticamente, esse tipo de variação não ocorre nessa última. Lucchesi (2009, p. 305) observa que, no PB, “só se registra um nível significativo de variação na concordância de gênero em certas comunidades rurais que passaram por um amplo e profundo contato linguístico em sua história”. Analisando dados de uma comunidade rural afro-brasileira, Helvécia, na Bahia, o autor busca traçar um paralelo dos padrões de variação na concordância de gênero encontrados em línguas crioulas de base lexical portuguesa com os encontrados nessa comunidade.

Em seu estudo, o autor observa um condicionamento linguístico da variação, interpretado em forma de três princípios: (a) Princípio da simplicidade - quanto mais simples a estrutura do SN, maior a aplicação da concordância. Assim, SNs com estrutura [Det $+\mathrm{N}]$ favorecem a concordância de gênero, em detrimento de SNs maiores (ver contraste entre 
[15] e [16]); (b) Princípio da integração - a aplicação da concordância é favorecida entre elementos mais integrados na estrutura, de forma que elementos pré-nucleares tendem a ser mais marcados do que elementos adjungidos à direita do núcleo (ver contrastre entre [17] e [18]), e (c) Princípio da saliência - núcleos nominais cuja morfologia de gênero seja mais marcada tendem a garantir maior aplicação da regra de concordância (ver contraste entre [19] e [20]):

(15) Eu falo $\underline{a \text { verdade }}$

(16) Chega lá é um maior confusão pá esses médico atende a gente

(LUCCHESI, 2009, p. 308, ex. 17 e 18)

(17) Não, trabalho na minha terra mesmo.

(18) E, aliás, num tem cobra nenhum que num é braba.

(LUCCHESI, 2009, p. 308, ex. 20 e 22)

(19) E adepois, junto com a sogra.

(20) Cada um tem um natureza.

(LUCCHESI, 2009, p. 307, ex. 24, p. 308, ex. 25)

Observando os dados das variedades africanas, verificamos que, em geral, a maioria dos casos de não-aplicação da concordância de gênero dá-se da seguinte maneira: o núcleo nominal é feminino e os elementos à esquerda estão no masculino. Isso ocorre com SNs simples (na forma Det $+\mathrm{N}$ ), como os apresentados em (21):

(21) a. Mesmo coisa (CVI18)

b. O semente (CVI19)

c. Muito criança (CVI9)

d. Outros crianças (CVI12)

e. Muito água (CVI18) 
Os dados na página anterior apontam para a não aplicação de concordância, mesmo em contextos que poderiam ser favorecedores da marcação, de acordo com o princípio da simplicidade observado em Lucchesi. Todavia, observamos também que os núcleos nominais nos exemplos em (21) não se flexionam em gênero, sugerindo-nos a interpretar a não aplicação da concordância pelo princípio da saliência.

Além das construções simples como as apresentadas em (21), encontramos também construções em que o núcleo nominal aparece em terceira posição. Novamente, os elementos pré-nucleares não concordam com o núcleo e, mais uma vez, podemos interpretar os dados em termos da aplicação do princípio da saliência, pelo fato de os núcleos nominais não se flexionarem para gênero:
a. O meu mãe (GBI2)
b. num determinado etnia (GBI5)
c. Os seus responsabilidade (GBI10)

Além desse tipo de construção, encontramos também a não-concordância em elementos adjungidos à direta do núcleo do $\mathrm{SN}$, sugerindo a atuação do princípio de integração:
a. Uma família bem conformado (GBI14)
b. Consequência tão perigoso (GBI16)

Por fim, encontramos também SNs com núcleo nominal masculino e marcação feminina no determinante ou possessivo pré-nominal, valendo referirmos que esse tipo de dado apareceu apenas no corpus do PGB e do PST:
a. minha casamento (GBI2)
b. na internato (GBI2)
c. na trompete (STI1)

Uma coincidência merece ser observada em relação aos dados em (24). Diferentemente do crioulo de Cabo Verde, em que ainda se pode observar uma variação na 
aplicação da concordância de gênero, os crioulos de Guiné Bissau e São Tomé, segundo Lucchesi (2009), eliminaram completamente a morfologia de gênero. Considerando que os dados do tipo apresentados em (24) foram exclusivos dos corpora do PST e do PGB, somos levados a indagar sobre a possibilidade de relacionar esses casos a uma possível interferência do crioulo falado nessas comunidades.

Sistematizando as nossas observações sobre a concordância de gênero, chegamos às seguintes afirmações:

(i) O tipo de regra linguística, nos termos defendidos por Labov (2003), é diferente entre o PA e as demais variedades africanas do português: na primeira, é categórica e, nas últimas, semicategórica, considerando os percentuais apresentados no quadro 2.

(ii) Em geral, a não-aplicação da concordância de gênero dá-se de maneira uniforme nas quatro variedades, a saber, com núcleo no feminino e elementos pré-nucleares no masculino;

(iii) É possível interpretarmos a maioria dos casos de não-aplicação da concordância de gênero como resultado da atuação de princípios condicionadores observados em Lucchesi (2009) para a variedade rural afro-brasileira de Helvécia. Assim, um paralelo entre as variedades africanas do português e a variedade de Helvécia pode ser observado;

(iv) Abre-se aqui um horizonte para a investigação acurada da concordância nominal em diferentes variedades do português, buscando observar, de um lado, um paralelo nos padrões manifestados em cada variedade, e, de outro, a investigação de fatores peculiares a cada variedade como responsável por diferentes padrões.

\section{Considerações finais}

Neste artigo procuramos discutir os padrões de concordância nominal de número e gênero em cinco variedades africanas do português, buscando traçar um paralelo com resultados apresentados em outros trabalhos para os padrões de $\mathrm{CN}$ encontrados em variedades do PB. 
A análise aqui empreendida permitiu observarmos a estruturação dos sintagmas para os casos de não aplicação da concordância, tendo em mente contextos em que verificamos semelhanças e diferenças entre as variedades africanas do português e o PB.

Nesse sentido, o trabalho investigativo realizado aponta para a necessidade de investigações mais amplas, no intuito de compreendermos as simetrias entre as diversas variedades do português, como também as assimetrias decorrentes, provavelmente, da interferência de fatores sociais.

\section{Referências}

ADRIANO, P. S. Tratamento morfossintático de expressão e estruturas frásicas do português em Angola: divergências em relação à norma europeia. Tese (Doutorado em Linguística). Évora: Universidade de Évora, 2014.

ARAKAKI, N. A. A obra "Moçambicanismos: para um léxico de usos do português moçambicano" e suas implicações socioculturais, políticas e linguísticas nos espaços lusobantófonos. Tese (Doutorado em Língua Portuguesa). São Paulo: Pontifícia Univerisdade Catílica de São Paulo, 2014.

BACELAR DO NASCIMENTO et al. Corpus África: as cinco variedades africanas do português. XXIII Encontro Nacional da Associação Portuguesa de Linguística, Lisboa, APL, 2008, p. 373-384.

BRANDÃO, S. F; VIEIRA, S. R. Concordância nominal e verbal: contribuições para o debate sobre o estatuto da variação em três variedades urbanas do português. Alfa, São Paulo, v. 53, no 3, 2012, p. 1035-1064.

CASTILHO, A. T. Nova gramática do português brasileiro. São Paulo: Editora Contexto, 2010.

CASTRO, P. P. As construções interrogativas, de tópico e de foco na língua crioula de Guiné-Bissau. Dissertação (Mestrado em Linguística). Rio de Janeiro: Universidade Federal do Rio do Janeiro, 2013.

COUTO, H.; EMBALÓ, F. Literatura, língua e cultura na Guiné-Bissau - um país da CPLP. Papia, v. 20, 2010.

FARACO, C. A.; VIEIRA, F. E. Gramáticas brasileiras: com a palavra, os leitores. São Paulo: Parábola, 2016.

FIGUEIREDO, C. F. G. A concordância plural variável no sintagma nominal do português reestruturado da comunidade de Almoxarife, São Tomé (Desenvolvimento das regras de concordância variáveis no processo de 
transmissão-aquisição geracional). Tese (Doutorado em Linguística). Macau: Faculdade de Ciências Sociais e Humanas, 2010.

GONÇALVES, P. (Dados para a) História da lingua portuguesa em Moçambique. Maputo, Jan. 2000.

Mudança linguística e variação no português de São Tomé. Actas do Colóquio Internacional São Tomé e Príncipe numa perspectiva interdisciplinar, diacrónica e sincrónica. Lisboa, 2012, p. 413-430.

Aspectos morfossintáticos da gramática do português de Moçambique: a concordância nominal e verbal. Cuadernos de la ALFAL, nº 7, 2015, p. 9-16.

GRACIOSA, D. Concordância verbal na fala culta carioca. Dissertação (Mestrado em Língua Portuguesa). Rio de Janeiro: Universidade Federal do Rio de Janeiro, 1991.

HAGEMEIJER, T. Clause structure in Santome. Tese (Doutorado em Letras). Lisboa: Universidade de Lisboa, 2007.

As línguas de S. Tomé e Príncipe. Revista de Crioulos de Base Lexical Portuguesa e Espanhola, n 1, 2009, p. 1-27.

INVERNO, L. Português vernáculo do Brasil e português vernáculo de Angola: reenstruturação parcial vs. mudança linguística. In: FERNÁNDEZ, M.; FERNÁNDEZFERREIRO, M.; VEIGA, N. V. (Org.). Criollos de base ibérica: ACBLPE. Madrid: Iberoamericana: Vervuert, 2004.

A transição de Angola para o português vernáculo: estudo morfossintáctico do sintagma nominal. In: CARVALHO, A. (Org.). Português em contacto. Madri; Frankfurt: Iberoamericana, Editorial Vervuert, no prelo.

JON-AND, A. Concordância variável de número no SN no português L2 de Moçambiquealgumas explicações sociais e linguísticas. Revista de Crioulos de Base Lexical Portuguesa e Espanhola, nº 2, 2010, p. 28-50.

LABOV, W. Some sociolinguistic principles. In: PAULSTON, C. B.; TUCKER, G. R. (Org.). Sociolinguistics: the essential readings. Oxford: Blackwell, 2003, p. 235-250.

LORENZINO, G. Afro-Portuguese creole $a$ : its Kwa origins and discourse pragmatics. African Journal of Languages and Linguistics, $\mathrm{n}^{\circ}$ 1, 1996, p. 45-67.

LUCCHESI, D. A diferenciação da língua portuguesa no Brasil e o contato entre línguas. Estudos de Lingüística Galega, no 4, 2012, p. 45-65.

. A concordância de gênero. In: LUCCHESI, D.; BAXTER, A.; RIBEIRO, I.

(Org.). O português afro-brasileiro. Salvador: Ed. da UFBA, 2009, p. 295-318.

Edufba, 2009.

BAXTER, A.; RIBEIRO, I. (Org.). O português afro-brasileiro. Salvador: 
MATTOS E SILVA, R. V. Diversidade e unidade: a aventura linguística do português. Revista ICALP, v. 11, no 12/13, 1988, p. 13-28.

MAURER, P. Principiense. In: MICHAELIS, S. M.; MAURER, P.; HASPELMATH, M.; HUBER, M. (Org.). The Survey of Pidgin and Creole Languages, v. 2: Portuguesebased, Spanish-based and French-based Language. Oxford University Press, 2013, p. 72-80.

MINGAS, A. A. O português em Angola: reflexões. VIII Encontro da Associação das Universidades de Língua Portuguesa, v. 1. Macau: Centro Cultural da Universidade de Macau, 1998, p. 109-126.

MOTA, M. A. Para uma tipologia da concordância sujeito-verbo, em português falado: contributos do português de Luanda e de Cabo Verde. Cuadernos de la ALFAL, $n^{\circ}$ 7, 2015, p. 17-35.

; MIGUEL, M.; MENDES, A. A concordância de P6 em português falado. Os traços pronominais e os traços de concordância. Papia, v. 22, no 1, 2012, p. 161-187.

NZAU, D. G. N.; VENÂNCIO, J. C.; SARDINHA, M. G. A. Em torno da consagração de uma variante angolana do português: subsídios para uma reflexão. Limite, n ${ }^{\circ}$ 7, 2013, p. 159-180.

OLIVEIRA, K.; SOLEDADE, J.; SANTOS, V. S. Concordância nominal. In: LOBO, T.; OLIVEIRA, K. (Org.). África à vista. Salvador: Edufba, 2009.

OLIVEIRA, M. S.; BAIO, J. P.; INJAI, B. F. A inserção do "contínuo português guineense" às variedades africanas do português. Língua, v. 15, nº 1, 2013, p. 130-137.

PETTER, M. M. T. Aspectos morfossintáticos comuns ao português angolano, brasileiro e maçambicano. Papia, no 19, 2009, p. 201-220.

PRATAS, F. O sistema pronominal do caboverdiano (variante de Santiago): questões de gramática. 2002. Dissertação (Mestrado em Linguística). Lisboa: Universidade Nova de Lisboa, 2002.

Tense features and argument structure in Capeverdean predicates. Tese (Doutorado em Linguística). Lisboa: Universidade Nova de Lisboa, 2007.

SCHERRE, M. M. P. Sobre a influência de três variáveis relacionadas na concordância nominal em português. In: SILVA, G. M. de O. e.; SCHERRE, M. M. P. (Org.). Padrões Sociolinguísticos: análise de fenômenos variáveis do português falado na cidade do Rio de Janeiro. Rio de Janeiro: Tempo brasileiro, 1998, p. 85-117.

SANTOS, V. G. Aspectos prosódicos do português de Guiné Bissau: a entoação do contorno neutro. Dissertação (Mestrado em Filologia e Língua Portuguesa). São Paulo: Universidade de São Paulo, 2015.

TEIXEIRA, E. S. P.; ALMEIDA, N. L. F. A indeterminação do sujeito no português angolano: uma comparação com o português do Brasil. PAPIA, v. 21, nº 1, 2011, p. 99111. 


\section{Abstract}

Sociolinguistic studies on verbal $(V A)$ and nominal $(\mathrm{N} A)$ agreement in Brazilian Portuguese (PB) and European Portuguese (PE) show that, in the first one, both $V A$ and $N A$ constitute a variable rule, and in $P E, N A$ is a categorical rule $(99.9 \%)$ and $V A$ is a semi-categorical rule $(98.9 \%) \quad(B R A N D \tilde{A O}$ and VIEIRA, 2012). In this paper, we focus our attention on the NA patterns of gender and number in five African Portuguese varieties (Angola, Mozambique, Sao Tome and Principe, Cape Verde and Guinea-Bissau) and, based on the three classes of language rules proposed by Labov (2003), we find, in the corpus of this research, constituted of 13,432 phrases, a variable and semicategoric rule for number $N A$. Regarding gender, the results suggest that the rule of application of agreement categorical in Angola and semi-categorical in the other varieties.

Keywords: Variation. Nominal agreement. Number. Gender. African varieties of Portuguese 